\title{
Oxidação de cianobactérias e seus metabólitos em sistemas de tratamento de água: o estado da arte
}

\author{
Oxidation of cyanobacteria and their \\ metabolites in water treatment facilities: the state of art
}

José Capelo Neto', Gayle Neycombe ${ }^{2}$

口-

\begin{abstract}
RESUMO
O problema causado pelas florações de cianobactérias em mananciais para abastecimento humano vem se tornando cada dia mais preocupante não só em regiões tropicais mas em todo o mundo. Os gestores dos sistemas de tratamento de água, muitas vezes, têm que recorrer ao uso da pré-oxidação como forma de auxiliar no tratamento apesar do incremento do potencial de liberação de metabólitos e da formação de subprodutos tóxicos. Por isso, a pré-oxidação tem sido vista como vilã, tornando-se um paradigma para os profissionais de tratamento de água. Este trabalho apresenta o estado da arte do conhecimento e evidências de que a pré e a pós-oxidação podem ser usadas com sucesso como primeira e última barreira à ameaça imposta pelas cianobactérias, desde que as características da água bruta sejam conhecidas. A partir daí, o oxidante, a dosagem e o tempo de contato podem ser selecionados e definidos com mais segurança, auxiliando na produção de água potável. Palavras-chave: pré-oxidação; cianobactérias; oxidação; metabólitos; estação de tratamento de água.
\end{abstract}

\begin{abstract}
The problem caused by cyanobacteria blooms in water sources for human consumption is becoming of more concern each day not only in tropical countries but worldwide. Water treatment systems often resort to the use of pre-oxidation as a form of auxiliary treatment although increasing the potential for release of metabolites and formation of toxic byproducts. Therefore, the pre-oxidation has often been seen as becoming a paradigm for the water treatment professionals. This paper presents the state of art and provides evidences that the pre and post-oxidation can be used successfully as first and last barrier to the problems caused by cyanobacteria provided that the raw water characteristics are known. From there, the oxidant, dosage and contact time can be selected and defined with greater confidence in order to produce drinking water.
\end{abstract}

Keywords: preoxidation; cyanobacteria; oxidation; metabolites; water treatment plant.

\section{INTRODUÇÃO}

Uma das alternativas para minimizar os problemas causados pelas florações de cianobactérias é a aplicação da pré-oxidação na água bruta antes da coagulação. Há evidências de que o tratamento com oxidantes pode ter um efeito positivo sobre os processos convencionais de tratamento, reduzindo a dose de coagulante e melhorando a qualidade da água tratada (Sukenik et al., 1987; Steynberg et al., 1996; Henderson; PARSONS; JEFFERSON, 2008; Chen \& Yeh, 2005; Ma et al., 2012a; Ma et al., 2012b). Um número de mecanismos tem sido proposto para explicar esse fenômeno, incluindo alterações das estruturas externas da célula, liberação de matéria orgânica intracelular (Ma \& Liu 2002) e inibição de movimentos (Steynberg et al., 1996; Petruševski; VAN BREEMEN; ALAERTS, 1996). No entanto, para melhorar a coagulação, mantendo-se a viabilidade econômica e minimizando-se a formação de subprodutos tóxicos, é fundamental a correta seleção do oxidante e da dosagem.

Existem considerações econômicas e químicas que devem ser feitas a respeito do uso da pré-oxidação: enquanto a aplicação de pré-oxidante pode reduzir a demanda de coagulante, faz-se necessária a determinação da dosagem ideal a partir da qual o custo adicional do oxidante começa a não compensar a economia feita pela redução das doses de coagulante; além disso, a oxidação de cianobactérias com cloro ou

1Professor do Departamento de Engenharia Hidráulica e Ambiental da Universidade Federal do Ceará (UFC) - Fortaleza (CE), Brasil.

2Pesquisadora sênior da Companhia de Saneamento do Sul da Austrália (SA Water) e membro da Australia Water Quality Center - Adelaide (South Australia State), Austrália. Endereço para correspondência: José Capelo Neto - Departamento de Engenharia Hidráulica e Ambiental (DEHA), Bloco 713 - Campus do Pici da UFC - 60451-970 Fortaleza (CE), Brasil.

Recebido: 07/O4/15 - Aceito: 23/08/16 - Reg. ABES: 148174 
ozônio, por exemplo, pode danificar as células e solubilizar metabólitos e matéria orgânica intracelular. Dessa forma, uma estratégia mais eficaz para o controle das cianobactérias no tratamento de água seria a aplicação de pré-oxidantes em doses que aumentem a remoção de células intactas, evitando a ruptura celular. Diversos tipos de oxidantes, em concentrações específicas, são capazes de aumentar a eficiência da coagulação sem afetar a integridade das células de cianobactérias ou, nos casos em que a integridade das células seja comprometida, conseguir a oxidação dos metabólitos intracelulares libertados. Alguns pesquisadores utilizaram doses elevadas o suficiente para superar a demanda de oxidante e destruir também os metabólitos (Ding et al. 2012; Daly; ho; brookes, 2007)

Este trabalho tem como objetivo apresentar o estado da arte do conhecimento tanto sobre os processos de pré-oxidação de cianobactérias quanto da oxidação de seus metabólitos e, assim, fornecer aos pesquisadores e companhias de saneamento uma visão integral das possibilidades e dos cuidados a serem adotados com esse procedimento. O texto é dividido em duas seções: a primeira, organizada por tipo de oxidante, aborda trabalhos sobre a oxidação de células de cianobactérias (pré-oxidação) e a concomitante oxidação de metabólitos intra e extracelulares durante o processo; a segunda apresenta relatos mais específicos sobre a oxidação de metabólitos dissolvidos de cianobactérias por vários oxidantes. Essa parte do trabalho mostra sua importância no momento em que parte dos metabólitos totais na água bruta podem já estar solubilizados antes da entrada na estação de tratamento de água e parte dos metabólitos intracelulares podem também ser solubilizados com a aplicação da pré-oxidação. Em razão do maior número de trabalhos publicados sobre esse tópico, essa seção foi dividida por oxidantes e cada oxidante, por metabólito.

\section{PRÉ-OXIDAÇÃO}

\section{Cloro}

O cloro é um oxidante forte que rapidamente leva à ruptura celular. Fan et al. (2013b) mostraram que, após um tempo de contato de $30 \mathrm{~min}$ com dose de $3 \mathrm{mg} . \mathrm{L}^{-1}$, 97\% de células de Microcystis aeruginosa foram lisadas. Resultados semelhantes foram observados por Zamyadi et al. (2010) estudando Amabaena circinalis (atualmente Dolichospermum circinalis). Ma et al. (2012b) também mostraram que a cloração (com dose entre 1 e $4 \mathrm{mg} . \mathrm{L}^{-1}$ e concentração x tempo (CT) entre 20 e $\left.80 \mathrm{mg} \cdot \mathrm{min} . \mathrm{L}^{-1}\right)$ induziu à libertação de $\mathrm{K}^{+}$, uma evidência da inativação de células, e proporcionou um efeito positivo na remoção de Microcystis aeruginosa. Esses autores também propuseram que tanto o mecanismo de coagulação por neutralização de cargas como o por varredura foram positivamente influenciados pela pré-cloração, mesmo não sendo observadas diferenças significativas entre as cargas superficiais das células cloradas e não cloradas.
De acordo com Cheng et al. (2009), $2 \times 10^{5}$ células. $\mathrm{mL}^{-1}$ em uma cultura de Cillindrospermopsis raciborskii foram completamente inativadas quando expostas a um CT de 4 mg.min. $\mathrm{L}^{-1}$ de cloro. Apesar do cloro causar uma rápida liberação de cianotoxinas através de ruptura da parede celular, ele também teve a capacidade de oxidá-las rapidamente. Zamyadi et al. (2012) mostraram que somente com um CT entre 120 e $300 \mathrm{mg} \cdot \mathrm{min} . \mathrm{L}^{-1}$ foi possível liberar as saxitoxinas (STX), microcistina-LR (MC-LR) e cilindrospermopsina (CYN) intracelulares e, subsequentemente, oxidá-las. Os autores observaram também que a oxidação das toxinas com cloro foi dependente do $\mathrm{pH}$ da água e que um CT adequado deve ser fornecido para garantir a oxidação eficiente de cada análogo de cianotoxina.

Uma das principais desvantagens da utilização do cloro como pré-oxidante é sem dúvida a formação de subprodutos halogenados (Ding et al. 2012; Zamyadi et al., 2012). Zamyadi et al. (2012) sugeriram, entretanto, que a qualidade da água bruta, especificamente a concentração de carbono orgânico dissolvido (COD), foi responsável por mais de $50 \%$ da formação dos subprodutos da desinfeção (SPD) e que a manutenção dos SPD abaixo de limites seguros $-80 \mu \mathrm{g} . \mathrm{L}^{-1}$ para trihalometano (THM) e $60 \mu \mathrm{g} . \mathrm{L}^{-1}$ para ácidos haloacéticos (AHA), de acordo com a USEPA (2006) - era possível, dependendo da qualidade da água bruta e do uso de valores adequados de CT, mesmo em uma floração de cianobactérias.

\section{Permanganato de potássio $\left(\mathrm{KMnO}_{4}\right)$}

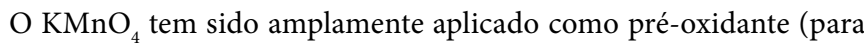
eliminar gosto, odor, ferro e manganês) e como controle biológico em estações de tratamento de água (Ma et al., 2012a; Rodriguez et al., 2007b). O pré-tratamento com $\mathrm{KMnO}_{4}$, combinado com a pós-cloração, pode diminuir a formação de SPD comparado ao uso da pós-cloração aplicada isoladamente (USEPA, 2006). Não há registros bibliográficos disponíveis que identifiquem a formação de SPD devido à aplicação de $\mathrm{KMnO}_{4}$. Além disso, o permanganato não interfere com outros processos de tratamento e todo o permanganato é reduzido formando precipitados de $\mathrm{MnO}_{2}$ os quais são removidos nos processos subsequentes se sua dosagem for adequada. Não é desejável, entretanto, manter um residual de $\mathrm{KMnO}_{4}$ por causa da sua tendência de atribuir uma coloração à água tratada.

Fan et al. (2013a; 2013b) estudaram os impactos do $\mathrm{KMnO}_{4}$ na integridade das células de cianobactérias e na liberação e degradação de metabólitos intra e extracelulares. Seus resultados demonstraram que, com uma dose entre 1 e 3 mg.L.-1, $98 \%$ de células de Microcystis aeruginosa permaneciam intactas; porém, com doses acima de $3 \mathrm{mg} . \mathrm{L}^{-1}$, foi observado um aumento no número de células comprometidas, o que causou o aumento da liberação de metabólitos intracelulares.

Ou et al. (2012) propuseram que a água bruta contendo Microcystis aeruginosa pode ser pré-oxidada com sucesso utilizando-se o $\mathrm{KMnO}_{4}$, 
que causa diminuição da capacidade fotossintética e remoção de MC-LR extracelular, mantendo intactas as células em suspensão. Utilizando doses cuidadosamente estudadas, a MC-LR intracelular pode, então, ser removida com as células de Microcystis aeruginosa através de tratamentos subsequentes como a clarificação e filtração.

Embora a oxidação com $\mathrm{KMnO}_{4}$ tenha sido efetiva na inativação de Microcystis aeruginosa e na remoção de MC-LR, a dosagem é um parâmetro vital de controle (Ou et al., 2012). Usando baixas doses (2-5 mg.L. $\left.\mathrm{L}^{-1}\right)$, a oxidação teve eficiência limitada na remoção de MC-LR intracelular. Por outro lado, com dosagens mais elevadas $\left(\geq 10 \mathrm{mg} . \mathrm{L}^{-1}\right)$ foi observada a lise celular e a remoção da MC-LR tanto extracelular quanto intracelular. O problema encontrado com doses elevadas foi o incremento do COD e o potencial incremento da formação de SPD no processo de pós-cloração.

Knappe et al. (2004) estudaram o efeito do CT de $\mathrm{KMnO}_{4}$ na eficiência do tratamento de água bruta enriquecida com cianobactérias. Eles relataram que a remoção de células melhorou com o aumento da dose de $\mathrm{KMnO}_{4}$ e do tempo de contato, atingindo uma redução de $80 \%$ de Microcystis aeruginosa e Anabaena flos-aquae com dosagem de 3 mg. $\mathrm{L}^{-1}$ e tempo de contato de $3 \mathrm{~h}$.

\section{Peróxido de hidrogênio}

Matthijs et al. (2012), usando uma dose de $2 \mathrm{mg} . \mathrm{L}^{-1}$ de peróxido de hidrogênio $\left(\mathrm{H}_{2} \mathrm{O}_{2}\right)$ em um lago holandês, reduziram a população de Planktothrix agardhii em 99\%, 10 dias após a aplicação do oxidante. A curva de redução da concentração de MC registrou um declínio similar ao da população de Planktothrix agardhii, mas com um atraso (lag) de 2 dias - ou seja, atingiu sua mínima concentração em 12 dias. Além disso, não foram observados impactos negativos significativos sobre as espécies fitoplanctônicas eucarióticas, zooplanctônicas ou na macrofauna 48 h após a adição do peróxido. Burson et al. (2014) também utilizaram $\mathrm{H}_{2} \mathrm{O}_{2}$ para controlar uma floração de Alexandrium ostenfeldii, produtoras de STX e espirolídeos (neurotoxinas de ação rápida que induzem sintomas semelhantes aos da STX) em águas naturais na Holanda. Após 27 h da adição de uma dosagem de 50 mg.L $L^{-1}$, uma concentração de 10,5 $\mu \mathrm{g}$. $\mathrm{L}^{-1}$ de STX foi reduzida para baixo do limite de detecção do método utilizado $\left(2,3 \mu \mathrm{g} \cdot \mathrm{L}^{-1}\right)$, e o número total de células viáveis de Alexandrium ostenfeldii foi reduzida em $99,9 \%$ a partir de uma concentração inicial de $5,5 \times 10^{6}$ células. $\mathrm{mL}^{-1}$. Nesse caso, entretanto, a aplicação de $\mathrm{H}_{2} \mathrm{O}_{2}$ teve um grande impacto sobre a comunidade planctônica. O volume do fitoplâncton total foi reduzido em $94 \%$ (de $9,75 \times 10^{4}$ para $0,57 \times 10^{4} \mathrm{~mm}^{3} \cdot \mathrm{L}^{-1}$ ) e a comunidade zooplanctônica de mais de $40 \times 10^{3}$ para menos de 15 indivíduos por litro após $50 \mathrm{~h}$. Observa-se, por meio desses dois casos, que o $\mathrm{H}_{2} \mathrm{O}_{2}$ pode apresentar um potencial para o controle de cianobactérias in situ, sem maiores impactos no restante da biota aquática, desde que usado em concentrações apropriadas.
Fan et al. (2014) investigaram os impactos da aplicação de $\mathrm{H}_{2} \mathrm{O}_{2} \mathrm{e}$ outros oxidantes sobre a integridade da membrana celular, densidade celular, liberação e degradação de metabólitos em águas contendo $7,0 \times 10^{5}$ células. $\mathrm{mL}^{-1}$ de Microcystis aeruginosa. A aplicação de doses entre 10 e $51 \mathrm{mg} . \mathrm{L}^{-1}$ de $\mathrm{H}_{2} \mathrm{O}_{2}$ danificou as membranas celulares ao longo de $48 \mathrm{~h}$, com o número de células intactas caindo a 6 e $4 \%$, respectivamente. Apesar dos danos causados à integridade das membranas, não foi observado aumento de microcistinas extracelulares após dois dias de contato com o $\mathrm{H}_{2} \mathrm{O}_{2}$. Além disso, a concentração total de microcistinas caiu em 80 e $90 \%$, respectivamente, a partir de uma concentração inicial de $52 \mu \mathrm{g} \cdot \mathrm{L}^{-1}$. Os autores defendem a ideia de que, como o $\mathrm{H}_{2} \mathrm{O}_{2}$ não forma subprodutos tóxicos no ambiente e é relativamente seletivo para cianobactérias em relação ao fitoplâncton eucariótico, ele poderia ser usado para controlar florações de cianobactérias e remover cianotoxinas de forma eficaz.

A contradição dos resultados encontrados nos trabalhos de Burson et al. (2014) e Fan et al. (2014) sobre os efeitos de dosagens similares de $\mathrm{H}_{2} \mathrm{O}_{2}$ na comunidade aquática, mais especificamente sobre o fitoplâncton eucariótico, pode estar relacionada com o tipo de biota aquática em cada sítio e com os diferentes ambientes nos quais os experimentos foram realizados. Enquanto Burson et al. (2014) experimentaram em água salobra, Fan et al. (2014) usaram águas residuais tratadas de uma lagoa de estabilização.

Fan et al. (2013b) desenvolveram estudos da cinética de decomposição de $\mathrm{H}_{2} \mathrm{O}_{2}$ em culturas de Microcystis aeruginosa com densidade celular inicial de 7,0x10 células. $\mathrm{mL}^{-1}$ e dosagens iniciais de $\mathrm{H}_{2} \mathrm{O}_{2}$ de 10 e $102 \mathrm{mg} . \mathrm{L}^{-1}$. As cianobactérias exerceram uma demanda de oxidante com cinética lenta, diminuindo o residual de $\mathrm{H}_{2} \mathrm{O}_{2}$ para 0,31 e $83 \mathrm{mg} . \mathrm{L}^{-1}$ após 8 dias da aplicação, respectivamente. Com doses de peróxido de hidrogênio de 10, 51 e $100 \mathrm{mg} . \mathrm{L}^{-1}$, aproximadamente 86, 46 e $51 \%$ das células mantiveram a integridade da membrana celular após um dia da adição do $\mathrm{H}_{2} \mathrm{O}_{2}$. Após dois dias, apenas 16, 31 e 7\% das células mantiveram a integridade da membrana. Os autores concluíram que, apesar de $\mathrm{o}_{2} \mathrm{O}_{2}$ não apresentar problemas com a geração de subprodutos tóxicos, cuidados devem ser tomados durante o manuseio em sua forma concentrada; também concluíram, principalmente, que sua cinética de reação é muito lenta para que seja de algum uso em sistemas de tratamento de água. Propuseram, ainda, que seu uso seria justificado no controle de cianobactérias no próprio manancial em substituição à aplicação de sulfato de cobre $\left(\mathrm{CuSO}_{4}\right)$.

\section{Dióxido de cloro}

Alguns estudos foram desenvolvidos com o objetivo de avaliar a integridade das células, a degradação dos metabólitos e a liberação de COD durante a oxidação das células de Microcystis aeruginosa utilizando dióxido de cloro $\left(\mathrm{ClO}_{2}\right)$ (Zhou et al., 2014a; Wert et al., 2014). Após a aplicação de uma dose de 1,0 mg. $\mathrm{L}^{-1}$ e $10 \mathrm{~min}$ de tempo de contato, 
Zhou et al. (2014a) observaram perda completa da integridade celular. Embora os autores tenham observado um aumento no COD após a lise celular e formação SPD durante o processo de pós-cloração da água, a concentração inicial de MC-LR $\left(10,1 \mu \mathrm{g} . \mathrm{L}^{-1}\right)$ intracelular foi reduzida para baixo do limite de detecção $\left(0,1 \mu \mathrm{g} \cdot \mathrm{L}^{-1}\right)$. Após $10 \mathrm{~min}$ de tempo de contato, o COD libertado aumentou de 0,60 para 1,25 mg. $\mathrm{L}^{-1} \mathrm{e}$ as concentrações de THM e AHA aumentaram de 9,10 para 29,24 $\mu$ g. $\mathrm{L}^{-1}$ e de 13,07 para 62,57 $\mu$ g. $\mathrm{L}^{-1}$ quando a dosagem de $\mathrm{ClO}_{2}$ foi aumentada de 0 a 1,0 mg. $\mathrm{L}^{-1}$, respectivamente. Wert et al. (2014) observaram que a oxidação das células de Microcystis aeruginosa com uma dosagem de $\mathrm{ClO}_{2}$ de 0,63 mg. $\mathrm{L}^{-1}$ levou a um aumento significativo de COD e MC-LR extracelular, enquanto uma dosagem mais elevada proporcionou a liberação e posterior oxidação da toxina, provocando um decréscimo da concentração de MC-LR total.

O problema com o dióxido de cloro, entretanto, é que ele reage com $\mathrm{OH}^{-}$, especialmente em condições alcalinas, formando clorito $\left(\mathrm{ClO}_{2}\right)^{-} \mathrm{e}$ clorato $\left(\mathrm{ClO}_{3}\right)$, o que deixa menos $\mathrm{ClO}_{2}$ disponível para a reação com as cianotoxinas. De acordo com Collivignarelli e Sorlini (2004), cerca de 68 e $9 \%$ do dióxido de cloro torna-se clorito e clorato, respectivamente. Além disso, o clorito e o clorato podem causar efeitos hematológicos negativos em mamíferos, tornando a utilização de doses mais altas inviável em tratamento de água potável (HO et al., 2006). A legislação brasileira especifica uma concentração máxima admissível de $1 \mathrm{mg} . \mathrm{L}^{-1}$ para clorito (Portaria MS No 2.914), mas não fixa qualquer limite para o clorato, enquanto a Organização Mundial da Saúde (OMS) sugere um valor de referência para clorito e clorato de $700 \mu \mathrm{g} . \mathrm{L}^{-1}$ (WHO, 2011). Dessa forma, doses de 1,0 a 1,5 mg. $\mathrm{L}^{-1}$ seriam um limite máximo teórico de aplicação em estações de tratamento de água.

\section{Outros oxidantes}

$\mathrm{O}$ ferrato $\left(\left[\mathrm{FeO}_{4}\right]^{-2}\right)$, um oxidante emergente, foi usado por Zhou et al. (2014b) como um reagente químico de dupla função (oxidante e coagulante) num teste de jarro tratando uma suspensão de Microcystis aeruginosa. $\mathrm{O}$ aumento da dosagem de 1 a $7 \mathrm{mg}$. $\mathrm{L}^{-1}$ substancialmente diminuiu a turbidez residual e aumentou a remoção de células. Atuando como oxidante, inativou $48 \%$ das células de Microcystis aeruginosa, visivelmente alterando sua morfologia. Embora não tenha promovido substancial lise celular, o ferrato aumentou o COD, os THM e os AHA, após a pós-cloração, em 25 e 65\%, respectivamente, com o referido aumento da dosagem. Durante tratamento de água potável, a pré-oxidação pode produzir carbono orgânico assimilável (COA) transformando macromoléculas de matéria orgânica dissolvida (MOD) em moléculas menores que, por sua vez, podem ser absorvidas mais facilmente pelas bactérias, gerando um risco potencial de recontaminação da água. Segundo Ramseier et al. (2011), a utilização de ferrato como pré-oxidante de células de Aphanizomenon gracile produziu significativas concentrações de COA $\left(>100 \mu \mathrm{g} \cdot \mathrm{L}^{-1}\right)$ a partir de uma dosagem de 4,6 mg. $\mathrm{L}^{-1}$ de ferrato em águas naturais com COD de 3,8 mg. $\mathrm{L}^{-1}$.

Wert et al. (2014) estudaram a aplicação de cloramina e ozônio em culturas puras de Lyngbya sp., Oscillatoria sp. e Microcystis aeruginosa. Os autores observaram que a aplicação de cloramina em culturas de Lyngbya sp., a aplicação de ozônio e cloramina em culturas de Oscillatoria sp e Microcystis aeruginosa aumentaram significativamente o COD. Observou-se que a oxidação de células de Microcystis aeruginosa com ozônio, com uma dose de $0,63 \mathrm{mg} . \mathrm{L}^{-1}$, produziu um aumento de MC-LR extracelular; já em doses mais elevadas, houve libertação e subsequente oxidação dessa toxina. A tendência anterior não foi observada quando os autores incrementaram a dosagem de cloramina (de 1 para $5 \mathrm{mg} . \mathrm{L}^{-1}$ ), já que um aumento na concentração extracelular de MC-LR foi observado devido à sua lenta taxa de reação com cloraminas. A oxidação das células de Oscillatoria sp. e das células de Lyngbya sp. com cloramina não proporcionou diminuição significativa das concentrações extracelulares de 2-Metilisoborneol (MIB) e de Geosmina quando as doses foram aumentadas. Já o incremento das doses de ozônio tendeu a diminuir a concentração de MIB a zero; não foi observada significativa diminuição na concentração de geosmina.

A limitação da dosagem de ozônio, a fim de controlar a formação de bromato em águas naturais com elevada concentração de brometo, pode restringir sua aplicação em estações de tratamento de água. Outro problema associado à ozonização é a formação de SPD orgânicos (por exemplo, aldeídos, ácidos carboxílicos e cetonas), os quais têm sido associados ao aumento do recrescimento bacteriano em sistemas de distribuição de água (Lechevallier et al., 1992).

\section{OXIDAÇÃO DE METABÓLITOS DISSOLVIDOS}

A Portaria n 2.914/2011 do Ministério da Saúde determina que análises sejam realizadas na água bruta e tratada com o objetivo de minimizar os riscos de contaminação da água para consumo humano com cianotoxinas. A legislação recomenda a análise semanal de clorofila-a como indicador de potencial aumento da densidade de cianobactérias. Outro controle importante que a Portaria determina é que, quando a densidade de cianobactérias exceder 20.000 células. $\mathrm{mL}^{-1}$, deve-se realizar análise de cianotoxinas na água do manancial, no ponto de captação.

Fawell, James e James (1994) desenvolveram estudos de toxicidade oral em camundongos e porcos, estabelecendo uma ingestão diária aceitável (TDI) para MC-LR de $0,04 \mu \mathrm{g} . \mathrm{Kg}^{-1}$ de peso corpóreo. Baseado nesse estudo, um limite máximo aceitável de $1 \mu \mathrm{g} . \mathrm{L}^{-1}$ de microcistinas em água para consumo humano foi adotado pela OMS (WHO, 1993) e pelo Ministério da Saúde do Brasil (Portaria MS No 2914). Não existem dados suficientes para o estabelecimento de um limite de concentração máximo aceitável para as saxitoxinas e cilindrospermopsina em água potável (Chorus \& Bartram, 1999) embora análises 
de eventos de intoxicações humanas demonstrem que a maioria dos casos esteve associada ao consumo de aproximadamente $200 \mu \mathrm{g}$ de saxitoxina equivalente (STX) por pessoa. Baseando-se nesses dados, Fitzgerald, Cunliffe e Burch (1999) propuseram $3 \mu \mathrm{g} . \mathrm{L}^{-1}$ como o limite máximo aceitável de saxitoxinas em água para consumo humano, referencial adotado por autoridades de saúde do sul da Austrália e do Brasil (Portaria MS No 2914). No caso da cilindrospermopsina, estudos toxicológicos desenvolvidos por Shaw et al. (2000) sugerem um limite máximo aceitável de $15 \mu \mathrm{g} . \mathrm{L}^{-1}$ para água potável apesar de a legislação brasileira sugerir um limite de $1 \mu \mathrm{g} . \mathrm{L}^{-1}$. No caso de detecção de gêneros de cianobactérias potencialmente produtores de anatoxina-A(s), a Portaria MS n 2.914/2011 recomenda apenas a análise da presença dessa cianotoxina.

\section{CLORO}

\section{Microcistinas}

Ao contrário do que foi apresentado por estudos anteriores desenvolvidos por Hoffman (1976), Himberg et al. (1989) e Keijola et al. (1988), o cloro tem demonstrado ser um oxidante eficaz na destruição de microcistinas (Nicholson; ROSITANO; BURCH, 1994; Tsuji et al., 1997; Senogles et al., 2003; Acero; RODRIGUEZ; MERILUOTO, 2005; Ho et al., 2006; Daly; HO; BROOKES, 2007; Merel; CLEMENT; THOMAS, 2010; Ma et al., 2012b; Li; DUAN; MULCAHY, 2012). Nicholson, Rositano e Burch (1994) mostraram que, mantendo um residual de cloro de pelo menos 0,5 mg. $\mathrm{L}^{-1}$ e tempo de contato de 30 min, a cloração foi eficaz na destruição de MC-LR e nodularina (NDL). Tsuji et al. (1997) observaram que uma dose de cloro de 2,8 mg.L.-1 com um tempo de contato de $30 \mathrm{~min}$ foi suficiente para a destruição de $99 \%$ da MC-LR. Li et al. (2012) mostraram que o cloro pode ser eficaz na degradação de MC-LR ainda que em esta esteja presente na água em concentrações menores que $10 \mathrm{ng} \cdot \mathrm{L}^{-1}$.

Nicholson, Rositano e Burch (1994) demonstraram que a destruição de MC-LR é dependente do pH, apresentando maior eficiência entre pH 5 e 8 . Valores de pH acima de 8 resultaram na diminuição da eficiência de oxidação. A explicação para tal observação recai sobre dois motivos principais: a reatividade do cloro é fortemente influenciada pelo $\mathrm{pH}$, uma vez que o equilíbrio ácido-base favorece a formação do ácido hipocloroso $(\mathrm{HOCl})$, um oxidante mais forte, em valores de $\mathrm{pH}$ menores que 8, enquanto em valores maiores a formação do íon hipoclorito $\left(\mathrm{ClO}^{-}\right)$, um oxidante fraco, é favorecida; e valores de $\mathrm{pH}$ menores que 5 podem afetar o grau de protonação das porções reativas (aminas e grupos fenolatos) da microcistina.

Diferentes análogos de MC apresentam diferentes taxas de reação com cloro. Ho et al. (2006) mostraram que a velocidade de reação obedece a seguinte tendência: $\mathrm{MC}-\mathrm{YR}>\mathrm{MC}-\mathrm{RR}>\mathrm{MC}-\mathrm{LR}>\mathrm{MC}-\mathrm{LA}$. Os autores observaram também que, mesmo com uma concentração residual de cloro de $0,5 \mathrm{mg} . \mathrm{L}^{-1}$ e tempo de contato de $30 \mathrm{~min}$, a MC-LA ainda estava presente em solução com concentração inicial acima de $1 \mu \mathrm{g} . \mathrm{L}^{-1}$, sugerindo que a identificação dos análogos de MC é importante para a otimização das práticas de cloração.

Zamyadi et al. (2012) conduziram experimentos de cloração com doses de cloro entre 2 e 5 mg. $\mathrm{L}^{-1}$ e pH de 8 , utilizando células cultivadas de Microcystis aeruginosa adicionadas em água de um reservatório australiano com concentração final de $5.0 \times 10^{4}$ e $2.0 \times 10^{5}$ células. $\mathrm{mL}^{-1}$. A redução de MC-LR total foi de 73 e 91\%, respectivamente, de uma concentração maior que $20 \mu \mathrm{g} . \mathrm{L}^{-1}$ para uma menor que $2 \mu \mathrm{g}$. $\mathrm{L}^{-1}$, com um CT de $220 \mathrm{mg} \cdot \mathrm{minL}^{-1}$. A cinética de reação foi de segunda ordem com constantes K entre 21 e 170 M.s. ${ }^{-1}$.

Segundo Nicholson, Rositano e Burch (1994), os subprodutos da cloração da microcistina apresentam uma toxicidade substancialmente menor que o composto original. Após ser tratado com cloro, o extrato aquoso de Microcystis aeruginosa contendo microcistina não foi capaz de induzir hepatotoxicidade aguda perceptível em camundongos suíços machos. Entretanto, Merel et al. (2009) ressaltam que, apesar de a mistura não apresentar mais hepatotoxicidade perceptível, ainda se desconhecem seus efeitos em outros órgãos; por conseguinte, uma investigação mais aprofundada deve ser realizada em amostras cloradas para avaliar a toxicidade global.

\section{Cilindrospermopsina e saxitoxinas}

CYN e STX são facilmente degradadas desde que um residual de cloro de $0,5 \mathrm{mg} . \mathrm{L}^{-1}$ seja mantido durante $30 \mathrm{~min}$ (Senogles et al., 2000; Newcombe \& Nicholson, 2002; Nicholson et al., 2003; Senogles et al., 2003; Rodriguez et al., 2007b; 2007c; Ho et al., 2008; 2009; Merel et al., 2010; Zamyadi et al., 2010; 2012). No entanto, o pH é novamente um parâmetro importante, podendo haver uma redução na eficiência da cloração da CYL e das SXTs se valores de $\mathrm{pH}$ abaixo de 6 forem mantidos.

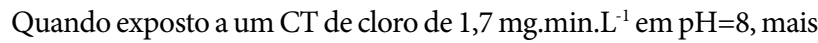
de metade da concentração inicial de $20 \mu \mathrm{g} . \mathrm{L}^{-1}$ de CYL foi degradada (Cheng et al., 2009). Merel et al. (2010) encontraram uma demanda de 5,3 mols de $\mathrm{Cl}_{2}$ por mol de CYL, sendo necessário um tempo mínimo de $20 \mathrm{~min}$, a uma temperatura de $20^{\circ} \mathrm{C}$ e $\mathrm{pH}$ de 7 . Os autores também apresentaram que, após um tempo de contato de $60 \mathrm{~min}$, a degradação da cianotoxina foi maior que 99,9\%, a partir de uma concentração inicial de $20 \mu \mathrm{M}\left(8,32 \mathrm{mg} \cdot \mathrm{L}^{-1}\right)$. Visto que, depois da filtração, uma concentração de CYL mil vezes menor que a utilizada na pesquisa anterior $\left(8,32 \mu \mathrm{g} . \mathrm{L}^{-1}\right)$ já representaria um elevado nível de contaminação, e que a cloração deve levar a concentrações de cloro residual livre maiores que $0,5 \mathrm{mg} . \mathrm{L}^{-1}$, a cloração pode ser considerada uma barreira segura para a remoção de CYL.

Senogles et al. (2003) demonstraram que o cloro tem uma melhor eficiência na degradação de SXTs em valores de pH maiores que 8. 
No entanto, um estudo mais recente mostrou uma destruição eficaz de SXTs em pH de 7 após um CT de cloro de 20 mg.min.L - $^{-1}$ (Ho et al., 2009). Usando água bruta enriquecida com células Anabaena cirlinalis em concentrações entre $5,0 \times 10^{4}$ e $2,0 \times 10^{5}$ células. $\mathrm{mL}^{-1}$, doses de cloro entre 2 e $5 \mathrm{mg} . \mathrm{L}^{-1}$ e $\mathrm{pH}$ de 8 , experimentos demonstraram que, para ambas as doses de cloro e concentrações celulares, SXTs intra e extracelular foram degradadas de concentrações iniciais de $4 \mathrm{e}$ $10 \mu \mathrm{g} . \mathrm{L}^{-1}$ para uma concentração total abaixo de $1 \mu \mathrm{g} . \mathrm{L}^{-1}$ após um CT de 60 mg.min.L.1 (Zamyadi et al., 2012). Zamyadi et al. (2012) também avaliaram a degradação de CYN em suspensões de Cylindrospermopsis raciborskii usando o mesmo procedimento operacional. Os resultados mostraram que elevadas remoções de CYN total podem ser alcançadas a partir de concentrações iniciais entre 6 e $24 \mu \mathrm{g} . \mathrm{L}^{-1}$ para concentrações finais abaixo de $2 \mu \mathrm{g} . \mathrm{L}^{-1}$ e eficiências de remoção variando de 83 a 99\%, em concordância com outros estudos recentes (Cheng et al., 2009; Merel et al., 2010).

\section{Anatoxina-A, MIB e geosmina}

Diversos autores relataram que o cloro foi ineficaz na remoção de anatoxina (ATX) e anatoxina-A (ATXA) (Carlile, 1994; Rositano \& Nicholson, 1994; Rapala et al., 2002; Rodriguez et al., 2007b; 2007c; Merel; CLEMENT; THOMAS, 2010). Rositano e Nicholson (1994) mostraram que mesmo com uma dosagem de cloro de $15 \mathrm{mg} . \mathrm{L}^{-1}$, durante 30 min e $\mathrm{pH} 7$, apenas $15 \%$ das $20 \mu \mathrm{g} . \mathrm{L}^{-1}$ de ATXA inicialmente presente foram removidas. De modo semelhante, MIB e geosmina não são afetadas pela cloração (Lalezary; pirbazari; mcguire, 1986; Glaze et al., 1990; Newcombe et al., 2014).

De forma geral, Merel, Clement e Thomas (2010b) mostraram que a cloração pode eficientemente degradar MC, CYL, NDL e SXT, mas não ATXA. Eles encontraram também que diferentes valores de $\mathrm{pH}$ são necessários para atingir uma remoção ideal de diferentes cianotoxinas: abaixo de 8 para MCs e NODs; 7 para CYL; acima de 9 para STXS. Assim, a cloração da água contendo uma mistura de cianotoxinas pode não conduzir a uma remoção ótima de todas as toxinas. Embora a cloração de MC e CYN tenha resultado na formação de 6 e 2 subprodutos, respectivamente, a toxicidade aguda foi reduzida drasticamente. Para STX e NDL, subprodutos da cloração não foram identificados e a mistura não apresentou toxicidade aguda em camundongos suíços com injeção intraperitoneal.

\section{OZÔNIO}

\section{Microcistinas}

O ozônio é o oxidante mais eficaz na destruição de MC e NDL desde que o residual seja mantido (Rositano; NICHOLSON; PIEROME, 1998; Rositano et al., 2001; Shawwa \& Smith, 2001; Hoeger; DIETRICH;
HITZFELD, 2002; Brooke et al., 2006). A eficiência do ozônio na destruição de cianotoxinas é, entretanto, dependente das características da água. Em particular, a matéria orgânica natural (MON) mostra ser um forte competidor pela reação com o ozônio, da mesma forma que acontece com outros oxidantes, podendo resultar na remoção incompleta de toxinas (Hart; fawell; croll, 1998; Mouchet \& Bonnélye, 1998; Rositano; NICHOLSON; PIEROME, 1998; Rositano et al., 2001; Shawwa \& Smith, 2001; Hoeger; DIETRICH; HITZFELD, 2002; Newcombe \& NiCHOLSON, 2002). Rositano, Nicholson e Pierome (1998) sugeriram que, uma vez que a demanda de ozônio da água tenha sido atingida, a remoção completa de $\mathrm{MC}$ pode ser conseguida na presença de qualquer residual com um tempo de contato de $5 \mathrm{~min}$. Esse comportamento foi confirmado em um estudo posterior (Newcombe et al., 2003), no qual a destruição de MC-LR e MC-LA para abaixo dos limites de detecção do método analítico $\left(0,1 \mu \mathrm{g} . \mathrm{L}^{-1}\right)$ foi conseguida, mesmo na presença de concentrações elevadas de COD (27 mg.L.-1).

Liu et al. (2010) investigaram a eficiência de três processos de oxidação $\left(\mathrm{O}_{3}, \mathrm{UV}, \mathrm{UV}+\mathrm{O}_{3}\right)$ de MC-LR. O uso de UV seguido de baixas doses de ozônio $\left(\mathrm{UV} / \mathrm{O}_{3}\right)$ apresentou um desempenho melhor do que os processos individuais de $\mathrm{O}_{3}$ ou UV. Os resultados demonstraram, também, os benefícios e as desvantagens da utilização de irradiação UV seguida por ozonização em baixas doses. No processo de ozonização em água filtrada, apenas $50 \%$ da concentração de MC-LR foi removida com uma dose de ozônio de $1,0 \mathrm{mg} . \mathrm{L}^{-1}$ e tempo de contato de $5 \mathrm{~min}$, em comparação a quase $100 \%$ de remoção de MC-LR em água ultrapura, indicando uma forte competição do COD pelo ozônio. Por outro lado, a remoção de MC-LR usando UV mostrou um melhor desempenho com a presença de baixas concentrações de COD do que com água isenta deste. No caso do processo combinado, UV seguido de ozônio, foi necessário um tempo de 5 min de irradiação, uma dosagem de ozônio de $0,2 \mathrm{mg} . \mathrm{L}^{-1}$ com tempo de contato de 5 min para que a concentração de MC-LR fosse reduzida para menos de $1 \mu \mathrm{g} . \mathrm{L}^{-1}$. Zong, Sun e Sun (2013) investigaram o mecanismo de reação, bem como a toxicidade biológica dos subprodutos da oxidação da MC-LR através $\mathrm{UV} / \mathrm{H}_{2} \mathrm{O}_{2}$, e, apesar de ter sido observada a formação de vários subprodutos, a maioria deles apresentou menor toxicidade que a MC-LR.

Miao et al. (2010) estudaram a degradação de microcistinas sob diferentes dosagens de $\mathrm{O}_{3}$. Os resultados mostraram que a ozonização foi eficaz na degradação da MC-LR e MC-RR e que a taxa de degradação de MC-RR era menor do que a MC-LR. A concentração inicial usada de MC-LR ou MC-RR foi de $50 \mu \mathrm{g} . \mathrm{L}^{-1}$ e a reação se realizou com diferentes razões molares de $\mathrm{O}_{3}: \mathrm{MC}$, durante $60 \mathrm{~s}$. A taxa de remoção aumentou de 29,5 para $92,1 \%$ e de 25,0 para $82,4 \%$, com o aumento da razão molar de $\mathrm{O}_{3}$ de 1 a 6 , para MC-LR e MC-RR, respectivamente. Os resultados da avaliação da toxicidade dos produtos finais da oxidação revelaram que a hepatotoxicidade das microcistinas foi reduzida ou eliminada por meio do processo de ozonização. 


\section{Saxitoxinas}

As doses necessárias de ozônio para degradar STX podem ser maiores do que as exigidas para microcistina e anatoxina (Carlile, 1994; Rositano; NICHOLSON; PIEROME, 1998; Rositano et al., 2001). Rositano et al. (2001) afirmaram que um tempo de contato de $5 \mathrm{~min}$ com um residual de ozônio maior que $0,2 \mathrm{mg} . \mathrm{L}^{-1}$ foi suficiente para a destruição da ATX abaixo do limite de detecção do método analítico. Em contraste, os autores averiguaram que as toxinas STX, GTX3, GTX2, C1 e C2 mostraram-se recalcitrantes ao ozônio, sendo necessárias doses consideravelmente mais elevadas que as necessárias para MC-LR, MC-LA e ANTA. Os autores atribuem isso às diferenças estruturais entre as toxinas: MCs contém um número de ligações duplas e aminoácidos facilmente oxidáveis, enquanto STX não contêm ligações duplas conjugadas ou porções aromáticas, resultando em menos locais para o ataque do oxidante.

Kaeding, Faulkner e Drikas (1999) mostraram que doses de ozônio entre 6 e 20 mg.L $L^{-1}$ foram necessárias para reduzir as concentrações de STX, C1, C2 e GTX2 para baixo dos limites de detecção, a partir de concentrações iniciais em torno de $170 \mu \mathrm{g} . \mathrm{L}^{-1}$. Os mesmos autores mostraram também que os diferentes análogos de saxitoxinas reagem diferentemente ao tratamento com ozônio, apresentando a seguinte tendência de velocidade de reação: toxinas do tipo STX>toxinas do tipo C>toxinas do tipo GTX.

\section{Cilindrospermopsina e anatoxina-A}

São poucos os estudos publicados sobre a ozonização de outras toxinas, por exemplo, a CYN. Craig et al. (1998) relataram que a CYN foi degradada eficientemente utilizando uma dose de ozônio de 1,5 mg.L. L $^{-1}$ com tempo de contato de 5 min em água com COD de 4 mg.L $L^{-1}$. Rodriguez et al. (2007b) mostraram que o ozônio pode ser eficaz na eliminação de uma variedade de cianotoxinas e determinaram que a velocidade de oxidação segue a seguinte tendência: $M C-L R>C Y N>A T X$. Nessa pesquisa, com a concentração de brometo $\left(50 \mu \mathrm{g} . \mathrm{L}^{-1}\right)$ presente na água natural e a dosagem de ozônio utilizadas, a formação de bromato devido à ozonização não ultrapassou a concentração de $10 \mu \mathrm{g} \cdot \mathrm{L}^{-1}$. Entretanto os autores ressaltaram que a formação de bromato pode ser um problema em águas com concentrações mais elevadas de brometo, principalmente quando se pretende assegurar a oxidação completa da ATX.

Onstad et al. (2007) estudaram a cinética química das reações de ozônio com a MC-LR, CYN e ATX em água milliQ. Em um pH de 8, as constantes de reação de segunda ordem $\left(\mathrm{K}_{\mathrm{O} 3}\right)$ foram de: $4,1 \times 10^{5} \mathrm{~mol}^{-1} \cdot \mathrm{L} \cdot \mathrm{s}^{-1}$

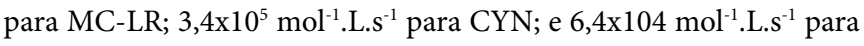
ATX. A degradação dessas toxinas em águas naturais foi também estudada, examinando a influência da matéria orgânica dissolvida na oxidação. Para a água com COD de 1,6 mg.L $\mathrm{L}^{-1}$, doses de ozônio de 0,2, 0,4, e 0,8 mg.L $\mathrm{L}^{-1}$ foram necessárias para a oxidação de 95\% de MC-LR,
CYN, e ATX, respectivamente. Para a águas com COD maiores que $13.1 \mathrm{mg} . \mathrm{L}^{-1}$, doses de ozônio maiores que $2 \mathrm{mg} . \mathrm{L}^{-1}$ foram necessárias para todas as toxinas.

\section{MIB e geosmina}

MIB e geosmina são álcoois alicíclicos cujas estruturas terciárias tornam as moléculas mais resistentes à ozonização que as cianotoxinas. Resultados conflitantes têm sido apresentados sobre a ozonização da MIB e geosmina, possivelmente pelo fato de sua eficácia ser fortemente dependente da qualidade da água, principalmente da matéria orgânica natural (MON) e da alcalinidade.

Estudos realizados por Lalezary, Pirbazari e McGuire (1986) demonstraram que uma dose de $2 \mathrm{mg} . \mathrm{L}^{-1}$ de $\mathrm{O}_{3}$ conseguiu redução de apenas $20 \%$ de geosmina em água isenta de $\mathrm{MON}$. Outros investigadores relataram que doses entre 2 e $7 \mathrm{mg} . \mathrm{L}^{-1}$ foram suficientes para destruir completamente MIB e geosmina em águas naturais (Lundgren; GRIMVALL; SAVENHED, 1988; Terashima, 1988). Ho et al. (2000) constataram que $1 \mathrm{mg} . \mathrm{L}^{-1}$ levou à destruição completa de MIB em água livre de MON. Jung \& Baek (2004), estudando a ozonização de MIB em água bruta, observaram remoção de MIB de $84,8 \%$ com uma dose de ozônio de 3,8 mg.L. $\mathrm{L}^{-1}$ e um tempo de contato de 6,4 min. Durante ensaios em planta-piloto, Ahn e Chae (2007) constataram que doses de 1 e 2 mg.L. $\mathrm{L}^{-1}$ e tempo de contato de 10 min não foram suficientes para redução de MIB e geosmina a concentrações abaixo de 15 ng. $\mathrm{L}^{-1}$. Trabalhos mais recentes também se mostraram inconclusivos. Yuan et al. (2013) relatam boa remoção de MIB e geosmina utilizando ozônio. Já Qi et al. (2013) descrevem o ozônio como ineficaz para o mesmo fim.

Morioka et al. (1993) estudaram a cinética de remoção de MIB e geosmina por ozonização na presença de substâncias húmicas (ácidos húmicos e fúlvicos). Eles determinaram que a remoção seguiu uma cinética de primeira ordem; e em águas com a presença de ácidos húmicos a taxa de remoção de MIB foi maior do que a registrada em águas com a presença de ácidos fúlvicos. O estudo demonstrou também que a oxidação da MIB e geosmina acontecia predominantemente através do radical hidroxil $\left(\mathrm{OH}^{\bullet}\right)$ e que as características das substâncias húmicas podem desempenhar um papel importante na oxidação desses metabólitos. Tal efeito também foi relatado por Ho, Croué e Newcombe (2004), que investigaram o efeito das características da MON na ozonização da MIB e geosmina. O estudo encontrou um aumento na remoção desses metabólitos em águas contendo frações de MON na faixa de maior peso molecular, sendo isso atribuído à maior reatividade dessa fração e, portanto, maior geração de radicais hidroxila.

A hipótese de que a maior alcalinidade aumentaria a estabilidade do ozônio, diminuindo, assim, a formação do radical hidroxila, e consequentemente diminuindo a remoção de MIB e geosmina foi verificada por Ho, Croué e Newcombe (2004) por meio do uso de bicarbonato de 
sódio. Concentrações de bicarbonato de sódio da ordem de $200 \mathrm{mg} \cdot \mathrm{L}^{-1}$ resultaram na diminuição da formação de radicais $\mathrm{OH}$ e menor remoção de MIB e geosmina.

\section{Outros oxidantes}

As cloraminas têm se mostrado ineficazes na oxidação de microcistinas (Hart \& Stott, 1993; Nicholson; ROSITANO; BURCH, 1994; Hart; fawell; croll, 1998; Rodriguez et al., 2007b; Ho et al., 2010). Karner et al. (2001) indicaram que, embora as cloraminas tenham induzido a alguma oxidação de microcistinas, foi necessário um tempo de reação superior a 10 h. Além disso, Rodriguez et al. (2007c) demonstraram que as cloraminas foram ineficazes na oxidação de CYN e ATX.

O dióxido de cloro $\left(\mathrm{ClO}_{2}\right)$ é um agente oxidante mais forte do que o cloro, altamente eficaz na degradação cianotoxinas (Kull et al., 2006; Rodriguez et al., 2007b; Zhou et al., 2014b), além de não reagir com a MON para formar THMs ou outros subprodutos orgânicos halogenados, sendo frequentemente utilizado como pré-oxidante. Zhou et al. (2014a), utilizando uma dosagem de $\mathrm{ClO}_{2}$ de $1,0 \mathrm{mg} . \mathrm{L}^{-1}$, conseguiram passar de uma concentração de MC-LR de $10,1 \mu \mathrm{g}$. $\mathrm{L}^{-1}$ para valores inferiores ao limite de detecção do método analítico $\left(0,1 \mu \mathrm{g}\right.$. $\left.\mathrm{L}^{-1}\right)$ em aproximadamente $10 \mathrm{~min}$. Wert et al. (2014) demonstraram que, quando $2.0 \times 10^{5}$ células. $\mathrm{mL}^{-1}$ de Microcystis aeruginosa foram expostas a uma dose de 0,63 mg. $\mathrm{L}^{-1}\left(\mathrm{CT}=560 \mathrm{mg} \cdot \mathrm{min} . \mathrm{L}^{-1}\right)$ de dióxido de cloro, a concentração de MC-LR extracelular aumentou de 3,3 para 10,1 $\mu \mathrm{g} . \mathrm{L}^{-1}$. Quando a dose foi aumentada para $5 \mathrm{mg} \cdot \mathrm{L}^{-1}\left(\mathrm{CT}=4100 \mathrm{mg} \cdot \mathrm{min} \cdot \mathrm{L}^{-1}\right)$, não houve aumento na concentração de MC-LR, indicando que qualquer MC-LR liberada foi subsequentemente oxidada.

O permanganato de potássio tem sido usado com sucesso na oxidação de microcistinas. Karner et al. (2001) relataram elevadas remoções de microcistinas em duas estações de tratamento de água, empregando permanganato como pré-oxidante. Carlile (1994) mostrou que o permanganato foi eficaz na remoção de MC-LR em 76, 88\% e abaixo do limite $\left(0,1\right.$ ug. $\left.\mathrm{L}^{-1}\right)$ de detecção do método quando as doses de $0,7,1,0 \mathrm{e}$ $>1,0 \mathrm{mg} . \mathrm{L}^{-1}$ foram utilizadas, respectivamente. Além disso, os mesmos autores mostraram que o permanganato foi eficaz para a remoção de ATX, com a remoção de mais de $85 \%$ e abaixo do limite de detecção quando doses de 0,5 e 1,0 mg. $\mathrm{L}^{-1}$ foram utilizadas, respectivamente. Fawell et al. (1993) também relataram remoções eficientes de microcistinas com permanganato em águas bruta e clarificada, observando que uma dose de $2 \mathrm{mg} . \mathrm{L}^{-1}$ resultou na oxidação de microcistinas para abaixo do limite de detecção do método utilizado $\left(0,1 \mu \mathrm{g} \cdot \mathrm{L}^{-1}\right)$. Da mesma forma, Rositano, Nicholson e Pierome (1998) mostraram que uma dose de $2 \mathrm{mg} . \mathrm{L}^{-1}$ de permanganato oxidou mais que $90 \%$ de MC-LR, a partir de uma concentração inicial de 1 mg.L $\mathrm{L}^{-1}$. Rodriguez et al. (2007a) mostraram que doses de permanganato entre 1,00 e 1,25 mg. $\mathrm{L}^{-1}$ foram suficientes para oxidar MC-LR, MC-RR e MC-YR para abaixo do valor de referência da OMS $\left(1 \mu \mathrm{g} . \mathrm{L}^{-1}\right)$. Os autores observaram uma reatividade ligeiramente maior do permanganato com a MC-RR e MC-YR em comparação com a MC-LR, de acordo com a ordem de oxidação por cloro das microcistinas apresentada por Ho et al. (2006).

Rodriguez et al. (2007b; 2007c) demonstraram que o permanganato foi uma opção viável para o tratamento de ATX, mas não para CYN. Cheng et al. (2009) investigaram a degradação de CYN pelo permanganato, cloramina e dióxido de cloro. Pouca ou nenhuma degradação de CYN foi observada utilizando permanganato com um CT de $360 \mathrm{mg} \cdot \mathrm{min} . \mathrm{L}^{-1}$, dióxido de cloro com um CT de $480 \mathrm{mg} \cdot \mathrm{min} . \mathrm{L}^{-1}$, e cloramina com um CT de 360 mg.min. $\mathrm{L}^{-1}$. As constantes de velocidade de segunda ordem para a reação com os radicais hidroxilas $\left(\mathrm{OH}^{\bullet}\right)$ em $\mathrm{pH} 7$ foram de $1,10 \pm 0,01 \times 10^{10} \mathrm{~mol}^{-1} . \mathrm{L} \cdot \mathrm{s}^{-1}$ para MC-LR, $5,50 \pm 0,01 \times 10^{9} \mathrm{~mol}^{-1} . \mathrm{L} \cdot \mathrm{s}^{-1}$ para CYN, e $3,00 \pm 0,02 \times 10^{9} \mathrm{~mol}^{-1} . \mathrm{L} \cdot \mathrm{s}^{-1}$ para ANTX (Onstad et al., 2007).

Da mesma forma que com o cloro, MIB e geosmina dissolvidas são recalcitrantes à oxidação com dióxido de cloro, cloraminas ou permanganato de potássio (Lalezary; PIRBAZARI; MCGUIRE, 1986; Glaze et al., 1990; Newcombe et al., 2014).

\section{CONCLUSÕES}

A pré-oxidação da água bruta pode aumentar o potencial de geração de subprodutos tóxicos e a liberação de conteúdo intracelular em águas para abastecimento. O cloro, por exemplo, pode romper as células de Microcystis aeruginosa com dosagens em torno de $3 \mathrm{mg} . \mathrm{L}^{-1}$. Entretanto, é possível combinar diferentes tipos de oxidantes, tempos de contato e dosagens apropriadas de forma a minimizar as desvantagens e melhorar etapas subsequentes como a coagulação e floculação, principalmente quando a água bruta apresenta densidades elevadas de cianobactérias. Um exemplo disso é o que ocorre com o $\mathrm{KMnO}_{4}$ : estudos comprovaram que com uma dose de até $3 \mathrm{mg} . \mathrm{L}^{-1}, 98 \%$ de células de Microcystis aeruginosa permaneciam intactas.

Existem evidências também de que as cianobactérias e seus metabólitos podem ser controlados antes mesmo de entrarem na estação de tratamento de água. O peróxido de hidrogênio tem demonstrado um potencial para controlar as cianobactérias no próprio lago sem os efeitos negativos apresentados por outros algicidas como o sulfato de cobre, por exemplo. Com a aplicação de dosagens em torno de $2 \mathrm{mg} \cdot \mathrm{L}^{-1}$ não foram observados impactos negativos sobre as espécies fitoplanctônicas eucarióticas, zooplanctônicas ou na macrofauna, enquanto com dosagens acima de $50 \mathrm{mg} . \mathrm{L}^{-1}$ a biota local foi afetada. Para uma aplicação ampla, entretanto, mais estudos sobre os impactos desse oxidante na biota de reservatórios específicos são necessários.

Quanto aos metabólitos, as toxinas mais comumente encontradas (microcistinas, saxitoxinas e cilindrospermopsina) foram facilmente removidas com oxidantes disponíveis nos sistemas de tratamento (cloro, por exemplo), desde que respeitados os tempos de contato, residuais e 
pHs apropriados. De forma genérica, com a aplicação de cloro em águas com valores de $\mathrm{pH}$ em torno de 8 e CTs entre 15 e 220 mg.min.L ${ }^{-1}$, autores concordam que as microcistinas, saxitoxinas e cilindrospermopsina, podem ser degradadas satisfatoriamente em águas dependendo das concentrações de matéria orgânica dissolvidas e das cianotoxinas.
Por outro lado, os metabólitos odoríferos (MIB e geosmina), apesar de não apresentaram impactos diretos à saúde humana, demonstram ser extremamente recalcitrantes à maioria dos oxidantes apresentados. Portanto, outros métodos de controle devem ser buscados como, por exemplo, a adsorção em carvão ativado.

\section{REFERÊNCIAS}

ACERO, J.L.; RODRIGUEZ, E.; MERILUOTO, J. (2005) Kinetics of reactions between chlorine and the cyanobacterial toxins microcystins. Water Research, v. 39, p. 1628-1638.

AHN, H. \& CHAE, S. (2007) Efficient taste and odor removal by water treatment plants around the Han River water supply system. Water Science and Technology, v. 55, n. 5, p. 103-109.

BRASIL, Ministério da Saúde. Portaria n. o 2.914, de 12 de Dezembro de 2011. Dispõe sobre normas de potabilidade de água para o consumo humano. Brasília: SVS, 2011.

BROOKE, S.; NEWCOMBE, G.; NICHOLSON, B.; KLASS, G. (2006) Decrease in toxicity of microcystins LA and LR in drinking water by ozonation. Toxicon, v. 48, p. 1054-1059.

BURSON, A.; MATTHIJS, H.C.P.; BRUIJNE, W.; TALENS, R.; RON HOOGENBOOM, R.; GERSSEN, A.; VISSER, P.M.; STOMP, M.; STEUR, K.; VAN SCHEPPINGEN, Y.; HUISMAN, J. (2014) Termination of a toxic Alexandrium bloom with hydrogen peroxide. Harmful Algae, v. 31, p. 125-135.

CARLILE, P.R. (1994) Further studies to investigate microcystin-LR and anatoxin-a removal from water. Swindon, UK: Foundation for Water Research Report, FR 0458.

CHEN, J.J. \& YEH, H.H. (2005) The mechanisms of potassium permanganate on algae removal. Water Research, v. 39, p. $4420-4428$.

CHENG, X.; SHI, H.; ADAMS, C.D.; TIMMONS, T.; MA, Y. (2009) Effects of oxidative and physical treatments on inactivation of Cylindrospermopsis raciborskiiand removal of cylindrospermopsin. Water Science \& Technology, v. 60, p. 689-697.

COLLIVIGNARELLI, C. \& SORLINI, S. (2004) Trihalomethane, chlorite and bromate formation in drinking water oxidation of Italian surface waters. Journal of Water Supply: Research Technology Aqua, v. 53, p. 159-168.

CHORUS, I. \& BARTRAM, J. (1999) Toxic Cyanobacteria in Water: a guide to their public health consequences, monitoring and management. Londres: E\&FN Spon.

CRAIG, K.; MAJEROWSKI, A.; BOWEN, B.; EVANS, G.M.; STEPHENS, A. (1998) Algal toxin and NOM removal using Ozone-BAC process under Australian conditions. Proceedings of the WaterTECH Conference, Brisbane, Australia.
DALY, R.I.; HO, L.; BROOKES, J.D. (2007) Effect of chlorination on Microcystis aeruginosa cell integrity and subsequent microcystin release and degradation. Environmental Science and Technology, v. 41, p. $4447-4453$

DING, Y.; GAN, N.Q.; LI, J.; SEDMAK, B.; SONG, L. (2O12) Hydrogen peroxide induces apoptotic-like cell death in Microcystis aeruginosa (Chroococcales, Cyanobacteria) in a dose-dependent manner. Phycologia, v. 51, p. 567-575.

FAN, J.; DALY, R.; HOBSON, P.; HO, L.; BROOKES, J. (2013a) Impact of potassium permanganate on cyanobacterial cell integrity and toxin release and degradation. Chemosphere, v. 92, n. 5, p. 529-534.

FAN, J.; HO, L.; HOBSON, P.; BROOKES, J. (2O13b) Evaluating the effectiveness of copper sulphate, chlorine, potassium permanganate, hydrogen peroxide and ozone on cyanobacterial cell integrity. Water Research, v. 47, n. 14, p. 5153-5164.

FAN, J.; HO, L.; HOBSON, P.; DALY, R.; BROOKES, J. (2014) Application of various oxidants for cyanobacteria control and cyanotoxin removal in wastewater treatment. Journal of Environmental Engineering, v. 140, p. 222-228.

FAWELL, J.K.; HART, J.; JAMES, H.A.; PARR, W. (1993) Blue-green algae and their toxins - analysis, toxicity, treatment and environmental control. Water Supply, v. 11, p. 109-121.

FAWELL, J.K.; JAMES, C.P.; JAMES, H.A. (1994) Toxins from blue-green algae: toxicological assessment of microcystin-LR and a method for its determination in water. Medmenham: Water Research Centre. 530p.

FITZGERALD, D.J.; CUNLIFFE, D.A.; BURCH, M.D. (1999) Development of health alerts for cyanobacteria and related toxins in drinking water in South Australia. Environmental Toxicology, v. 14, n. 1, p. 203-209.

GLAZE, W.H.; SCHEP, R.; CHAUNCEY, W.; RUTH, E.C.; ZARNOCH, J.J.; AIETA, E.M.; TATE, C.H.; MCGUIRE, M.J. (1990) Evaluating oxidants for the removal of model taste and odor compounds from a municipal water-supply. Journal of American Water Works Association, v. 82, n. 5, p. 79-84.

HART, J.; FAWELL, J.K.; CROLL, B. (1998) The fate of both intra- and extracellular toxins during drinking water treatment. Water Supply, v. 16, p. 611-616.

HART, J. \& STOTT, P. (1993) Microcystin-LR removal from water. Report No. FRO367. Swindon, UK: Foundation for Water Research. 126p. 
HENDERSON, R.; PARSONS, S.A.; JEFFERSON, B. (2008) The impact of algal properties and pre-oxidation on solid-liquid separation of algae. Water Research, v. 42, p. 1827-1845.

HIMBERG, K.; KEIJOLA, A.M.; HIISVIRTA, L.; PYYSALO, H.; SIVONEN, $K$. (1989) The effect of water treatment processes on the removal of hepatotoxins from Microcystis and Oscillatoria cyanobacteria: a laboratory study. Water Research, v. 23, p. 979-984.

HO, L.; CROUÉ, J.; NEWCOMBE, G. (2004) The effect of water quality and NOM character on the ozonation of MIB and geosmin. Water Science and Technology, v. 49, n. 9. p. 249-255.

HO, L.; KAYAL, N.; TROLIO, R.; NEWCOMBE, G. (2010) Determining the fate of Microcystis aeruginosa cells and microcystin toxins following chloramination. Water Science \& Technology, v. 62, p. 442-450.

HO, L.; NEWCOMBE, G.; CROUÉ, J.P.; KLASS, G. (2000) The effect of NOM character on the Ozonation of MIB and geosmin. Proceedings of Water Quality Technology Conference, Salt Lake City, Utah.

HO, L.; ONSTAD, G.; VON GUNTEN, U.; RINCK-PFEIFFER, S.; CRAIG, K.; NEWCOMBE, G. (2006) Differences in the chlorine reactivity of four microcystin analogues. Water Research, v. 40, p. 1200-1209.

HO, L.; SLYMAN, N.; KAEDING, U.; NEWCOMBE, G. (2008) Optimizing PAC and chlorination practices for cylindrospermopsin removal. Journal of the American Water Works Association, v. 100, p. 88-96.

HO, L.; TANIS-PLANT, P.; KAYAL, N.; SLYMAN, N.; NEWCOMBE, G. (2009) Optimising water treatment practices for the removal of Anabaena circinalis and its associated metabolites, geosmin and saxitoxins. Journal of Water and Health, v. 7, p. 544-556.

HOEGER, S.J.; DIETRICH, D.R.; HITZFELD, B.C. (2002) Effect of ozonation on the removal of cyanobacterial toxins during drinking water treatment. Environmental Health Perspectives, v. 110, p. 1127-1132.

HOFFMAN, J.R.H. (1976) Removal of Microcystis toxins in water purification processes. Water SA, v. 2, p. 58-60.

JUNG, S.W. \& BAEK, K.H. (2004) Treatment of tasteand odor material by oxidation and adsorption. Water Science and Technology, v. 49, n. 9, p. 289-295.

KAEDING, U.; FAULKNER, M.; DRIKAS, M. (1999) Ozone treatment of water containing high concentrations of natural organic matter. In: Federal AWWA Convention, 18., Adelaide, Australia. Proceedings... Australia.

KARNER, D.A.; STANDRIDGE, J.H.; HARRINGTON, G.W.; BARNUM, P. (2001) Microcystin algal toxins in source and finished drinking water. Journal of the American Water Works Association, v. 93, p. 72-81.

KEIJOLA, A.M.; HIMBERG, K.; ESALA, A.L.; SIVONEN, K.; HIISVIRTA, L. (1988) Removal of cyanobacterial toxins in water treatment processes: laboratory and pilot-scale experiments. Toxicity Assessment: an International Journal, v. 3, p. 643-656.

KNAPPE, R.; DETLEF, R.U.; BELK, C.; BRILEY, D.S.; GRANDY, S.R.; RASTOGI, N.; RIKE, A.H. (2004) Algae detection and removal strategies for drinking water treatment plants. Denver, USA: AWWA Research Foundation.

KULL, T.P.J.; SJOVALL, O.T.; TAMMENKOSKI, M.K.; BACKLUND, P.H.; MERILUOTO, J.A.O. (2006) Oxidation of the cyanobacterial hepatotoxin microcystin-LR by chlorine dioxide: influence of natural organic matter. Environmental Science Technology, v. 40, p. $1504-1510$.

LALEZARY, S.; PIRBAZARI, M.; MCGUIRE, M.J. (1986) Oxidation of five earthy-musty taste and odor compounds. Journal of the American Water Works Association, v. 78, n. 3, p. 62-69.

LECHEVALLIER, M.W.; BECKER, W.C.; SCHORR, P.; LEE, R.G. (1992) Evaluating the performance of biologically active rapid filters. Journal of the American Water Works Association, v. 84, n. 4, p. 136-146.

LI, W.; DUAN, J.; MULCAHY, D.E. (2012) Kinetic characteristics of oxidation of Microcystin-LR low concentration by chlorine and permanganate. Journal of Water Supply: Research and Technology - AQUA, v. 61, n. 2, p. 82-93.

LIU, X.; CHEN, Z.; ZHOU, N.; SHEN, J.; YE, M. (2010) Degradation and detoxification of microcystin-LR in drinking water by sequential use of UV and ozone. Journal of Environmental Sciences, v. 22, n. 12, p. 1897-1902.

LUNDGREN, B.V.; GRIMVALL, A.; SAVENHED, R. (1988) Formation and removal of off-flavour compounds during ozonation and filtration through biologically active sand filters. Water Science and Technology, v. 20, n. 8, p. 245-253.

MA, J. \& LIU, W. (2002) Effectiveness and mechanism of potassium ferrate $(\mathrm{VI})$ preoxidation for algae removal by coagulation. Water Research, v. 36, p. 871-878.

MA, M.; LIU, R.; LIU, H.; QU, J. (2012a) Effect of moderate preoxidation on the removal of Microcystis aeruginosa by $\mathrm{KMnO} 4$ Fe(II) process: significance of the in-situ formed Fe(III). Water Research, v. 46, p. 73-81.

MA, M.; LIU, R.; LIU, H.; QU, J.; JEFFERSON, W. (2O12b) Effects and mechanisms of pre-chlorination on Microcystis aeruginosa removal byalum coagulation:Significance of the released intracellular organic matter. Separation and Purification Technology, v. 86, p. 19-25.

MATTHIJS, H.C.P.; VISSER, P.M.; REEZE, B.; MEEUSE, J.; SLOT, P.C.; WIJN, G.; TALENS, R.; HUISMAN, J. (2012) Selective suppression of harmful cyanobacteria in an entire lake with hydrogen peroxide. Water Research, v. 46, p. 1460-1472.

MEREL, S.; CLEMENT, M.; MOUROT, A.; FESSARD, V.; THOMAS, O. (2010). Characterization of cylindrospermopsin chlorination. Science of the Total Environment, v. 408, p. 3433-3442.

MEREL, S.; CLEMENT, M.; THOMAS, O. (2010) State of the art on cyanotoxins in water and their behaviour towards chlorine. Toxicon, v. 55, p. 677-691.

MEREL, S.; LEBOT, B.; CLEMENT, M.; SEUX, R.; THOMAS, O. (2009) MS identification of microcystin-LR chlorination by-products. Chemosphere, v. 74, n. 6, p. 832-839. 
MIAO, H.F.; QIN, F.; TAO, G.J.; TAO, W.Y.; RUAN, W.Q. (2010) Detoxification and degradation of microcystin-LR and -RR by ozonation. Chemosphere, v. 79, p. 355-361. Disponível em: http:// www.sciencedirect.com/science/article/pii/S0045653510001700. Acesso em: 04 abr. 2015.

MORIOKA, T.; MOTOYAMA, N.; HOSHIKAWA, H.; MURAKAMI, A.; OKADA, M.; MONIWA, T. (1993) Kinetic analysis on the effect of dissolved inorganic and organic substances in raw water on the ozonation of geosmin and 2-MIB. Ozone Science and Engineering, v. 15, n. 1, p. 1-18.

MOUCHET, P.; BONNÉLYE, V. (1998). Solving algae problems: French expertise and world-wide applications. J. Water SRT, Aqua., 47: 125-141.

NEWCOMBE, G.; COOK, D.; BROOKE, S.; HO, L.; SLYMAN, N. (2003) Treatment options for microcystin toxins: similarities and differences between variants. Environmental Technology, v. 24, p. 299-308.

NEWCOMBE, G.; DREYFUS, J.; MONROLIN, J.; PESTANA, C.; REEVE, P.; SAWADE, E.; HO, L.; CHOW, C.; KRASNER, S.W.; YATES, R.S. (2O14) Optimizing conventional treatment for removal of cyanobacteria and toxins. Water Research Foundation, in press.

NEWCOMBE, G. \& NICHOLSON, B.C. (2002) Treatment options for the saxitoxin class of cyanotoxins. Water Science \& Technology: Water Supply, v. 2, p. 271-275.

NICHOLSON, B.C.; ROSITANO, J.; BURCH, M.D. (1994) Destruction of cyanobacterial peptide hepatotoxins by chlorine and chloramine. Water Research, v. 28, p. 1297-1303.

NICHOLSON,B.C.;SHAW, G.R.; MORRALL, J.;SENOGLES,P.J.; WOODS, T.A.; PAPAGEORGIOU, J.; KAPRALOS, C.; WICKRAMASINGHE, W.; DAVIS, B.C.; EAGLESHAM, G.K.; MOORE, M.R. (2003) Chlorination for degrading saxitoxins (paralytic shellfish poisons) in water. Environmental Technology, v. 24, p. 1341-1348.

ONSTAD, G.D.; STRAUCH, S.; MERILUOTO, J.; CODD, G.A.; VON GUNTEN, U. (2007) Oxidative elimination of cyanotoxins: comparison of ozone, chlorine, chlorine dioxide and permanganate. Environmental Science and Technology, v. 41, p. 4397-4404.

OU, H.; GAO, N.; WEI, C.; DENG, Y.; QIAO, J. (2012) Immediate and long-term impacts of potassium permanganate on photosynthetic activity, survival and microcystin-LR release risk of Microcystis aeruginosa. Journal of Hazardous Materials, v. 219-220, p. 267-275.

PETRUSEVSKI, B.; VAN BREEMEN, A.N.; ALAERTS, G. (1996) Effect of permanganate pre-treatment and coagulation with dual coagulants on algae removal in direct filtration. Journal of Water Supply: Research and Technology - AQUA, v. 45, p. 316-326.

QI, F; XU, B.B.; FENG, L.; CHEN, Z.L.; ZHANG, L.Q.; SUN, D.Z. (2O13) Formation of aldehyde during ozonation of taste and odour compounds in water. Journal of Water Supply Research and Technology-Aqua, v. 62, n. 2, p. 120-128.

RAMSEIER, M.K.; PETER, A.; TRABER, J.; VON GUNTEN, U. (2O11) Formation of assimilable organic carbon during oxidation of natural waters with ozone, chlorine dioxide, chlorine, permanganate, and ferrate. Water Research, v. 45, p. 2002-2010.

RAPALA, J.; LAHTI, K.; RÄSÄNEN, L.A.; ESALA, A.L.; NIEMELÄ, S.I; SIVONEN, K. (2002) Endotoxins associated with cyanobacteria and their removal during drinking water treatment. Water Research, v. 36, p. $2627-2635$

RODRIGUEZ, E.; MAJADO, M.E.; MERILUOTO, J.; ACERO J.L. (2007a) Oxidation of microcystins by permanganate: reaction kinetics and implications for water treatment. Water Research, v. 41, p. 102-110.

RODRIGUEZ, E.; ONSTAD, G.D.; KULL, T.P.J.; METCALF, J.S.; ACERO, J.L.; VON GUNTEN, U. (2007b) Oxidative elimination of cyanotoxins: comparison of ozone, chlorine, chlorine dioxide and permanganate. Water Research, v. 41, p. 3381-3393.

RODRIGUEZ, E.; SORDO, A.; METCALF, J.S.; ACERO, J.L. (2007c) Kinetics of the oxidation of cylindrospermopsin and anatoxin-a with chlorine, monochloramine and permanganate. Water Research, v. 41, p. 2048-2056.

ROSITANO, J.; NEWCOMBE, G.; NICHOLSON, B.; SZTAJNBOK, P. (2001) Ozonation of NOM and algal toxins in four treated waters. Water Research, v. 35, p. 23-32.

ROSITANO, J. \& NICHOLSON, B.C. (1994) Water treatment techniques for the removal of cyanobacterial toxins from water Adelaide, Australia: Australian Centre for Water Quality Research Report. 135p.

ROSITANO, J.; NICHOLSON, B.C.; PIERONNE, P. (1998) Destruction of cyanobacterial toxins by ozone. Ozone: Science \& Engineering, v. 20, p. $223-238$.

SENOGLES, P.J.; SEAWRIGHT, A.; SHAW, G.; WICKRAMISINGH, W.; SHAHIN, M. (2003) Toxicological aspects of treatment to remove cyanobacterial toxins from drinking water determined using the heterozygous P53 transgenic mouse model. Toxicon, v. 41, p. 979-988.

SENOGLES, P.J.; SHAW, G.; SMITH, M.; NORRIS, R.; CHISWELL, R.; MUELLER, J.;SADLER, R.; EAGLESHAM, G. (2000) Degradation of the cyanobacterial toxin cylindrospermopsin, from Cylindrospermopsis raciborskii, by chlorination. Toxicon, v. 38, p. 1203-1213.

SHAW, G.; SEAWRIGHT, A.; SHAHIN, M.; SENOGLES, P.; MUELLER, J.; MOORE, M. (2000) The cyanobacterial toxin, Cylindrospermopsin: human health risk assessment. Report from the National Research Center for Environmental Toxicology - Australia. Queensland: National Research Center for Environmental Toxicology. 110p.

SHAWWA, A.R. \& SMITH, D.W. (2001) Kinetics of microcystin-LR oxidation by ozone. Ozone: Science \& Engineering, v. 23, p. 161-170.

STEYNBERG, M.C.; GUGLIELMI, M.M.; GELDENHUYS, J.C.; PIETERSE, A.J.H. (1996) Chlorine and chlorine dioxide: pre-oxidants used as algaecide in potable water plants. Journal Water SRT - Aqua, v. 45, n. 4, p. 162-170. Disponível em: https://www.researchgate. net/publication/279563861_Chlorine_and_chlorine_dioxide_Preoxidants_used_as_algocide_in_potable_water_plants. Acesso em 04 abr. 2015 
SUKENIK, A.; WYMAN, K.D.; BENNETT, J.; FALKOWSKI, P.G. (1987) Light-saturated photosynthesis - limitation by electron transport or carbon fixation? Biochimica et Biophysica Acta, v. 891, p. 205-215.

TERASHIMA, K. (1988) Reduction of musty odor substances in drinking water - a pilot plant study. Water Science and Technology, v. 20, n. $8 / 9$, p. $275-281$.

TSUJI, K.; WATANUKI, T; KONDO, F; WATANABE, M.F; NAKAZAWA, H.; SUZUKI, M.; UCHIDA, H.; HARADA, K.I. (1997) Stability of microcystins from cyanobacteria - IV. Effect of chlorination on decomposition. Toxicon, v. 35, p. 1033-1041.

USEPA - Agência de Proteção Ambiental dos Estados Unidos. (2006) National Primary Drinking Water Standards. Disponível em: $<$ http://www.epa.gov/safewater/consumer/pdf/mcl.pdf>. Acesso em: abr. 2015

WERT, E.C.; KORAK, J.A.; TRENHOLM, R.A.; ROSARIO-ORTIZ, F.L. (2014) Effect of oxidant exposure on the release of intracellular microcystin, MIB, and geosmin from three cyanobacteria species. Water Research, v. 52, p. 251-259.

WHO - World Health Organization. (1993) Guidelines for drinkingwater quality. 2. ed. Geneve.

WHO - World Health Organization. (2011) Guidelines for drinkingwater quality. 4. ed. Geneve.
YUAN, B.L:; XU, D.M.; LI, F.; FU, M.L. (2013) Removal efficiency and possible pathway of odor compounds (2-methylisoborneol and geosmin) by ozonation. Separation and Purification Technology, v. 117, p. $53-58$.

ZAMYADI, A.; HO, L;: NEWCOMBE, G.; BUSTAMANTE, H.; PRÉVOST,M. (2012) Fate of toxic cyanobacterial cells and disinfection by-products formation after chlorination. Water Research, v. 46, p. 1524-1535.

ZAMYADI, A.; HO, L.; NEWCOMBE, G.; DALY, R.I.; BURCH, M.; BAKER, P.; PRÉVOST, M. (2010) Release and oxidation of cellbound saxitoxins during chlorination of Anabaena circinalis cells. Environmental Science \& Technology, v. 44, p. 9055-9061.

ZHOU, S.; SHAO, Y.; GAO, N.; LI, L.; DENG, J.; ZHU, M.; ZHU, S. (2O14a) Effect of chlorine dioxide on cyanobacterial cell integrity, toxin degradation and disinfection by-product formation. Science of the Total Environment, v. 482-483, p. 208-213.

ZHOU, S.; SHAO, Y.; GAO, N.; ZHU, S.; LI, L.; DENG, J. (2O14b) Removal of Microcystis aeruginosa by potassium ferrate (VI): impacts on cells integrity, intracellular organic matter and disinfection by-products formation. Chemical Engineering Journal, v. 251, p. 304-309.

ZONG, W.; SUN, F.; SUN, X. (2013) Oxidation by-products formation of microcystin-LR exposed to UV/H2O2: toward the generative mechanism and biological toxicity. Water Research, v. 47 , p. 3211-3219. 